\title{
High-resolution X-ray structure of methyl salicylate, a time-honored oily medicinal drug, solved by crystalline sponge method
}

\author{
Masatoshi Kawahata ${ }^{a}{ }^{*}$, Shinsuke Komagawa ${ }^{a}$, Kazuaki Ohara ${ }^{a}$, Makoto Fujita ${ }^{\text {b }}$ and Kentaro Yamaguchi \\ a, $*$ \\ ${ }^{a}$ Faculty of Pharmaceutical Sciences at Kagawa Campus, Tokushima Bunri University, 1314-1 Shido, Sanuki, Kagawa 769-2193, Japan \\ ${ }^{b}$ Department of Applied Chemistry, Graduate School of Engineering, The University of Tokyo and JST-ACCEL, 7-3-1 Hongo, Bunkyo-ku, Tokyo 113-8656, \\ Japan.
}

\section{ARTICLE INFO}

Article history:

Received

Received in revised form

Accepted

Available online

\section{Keywords:}

Structure Determination

Single Crystal X-Ray Diffraction

Medicinal Drug

Crystalline Sponge Method

\section{ABSTRACT}

The recently developed crystalline sponge method, which employs single-crystal X-ray diffraction to determine the structure of an analyte present in liquid or oil and having a low melting point, was adopted for measuring methyl salicylate, a time-honored oily medicinal drug. Six independent molecules existed in the asymmetric unit of the crystalline sponge. We succeeded in solving the fine structure of methyl salicylate, which had almost no unassigned fragment and/or solvent in the void spaces constructed by the network complex, and discussed the precise geometry of this molecules. All the methyl salicylate molecules were stacked in layers. By using the crystalline sponge method, the molecular diversity and the related specific homogeneous molecular interactions of methyl salicylate were observed in the lone space in the framework.

2009 Elsevier Ltd. All rights reserved.
Thorough analysis of the three-dimensional structure obtained by X-ray crystallography of a target molecule is one of the key steps in drug discovery and drug design. Although an enormous amount of time and cost is spent on new drug discovery, many efforts end in failure. It is said that the precise molecular structure analysis of target compounds as well as target receptor proteins is necessary for success. X-ray single-crystal diffraction (SCD) is one of the most powerful tools for three-dimensional molecular structure determination. SCD provides the geometrical parameters of a molecule, including bond lengths, bond angles, and torsion angles, in high resolution, as well as the whole shape of the molecule. In addition, SCD can elucidate the absolute configuration of the molecule under certain favorable conditions. However, this method requires a pure single crystal. Thus, SCD of compounds in the powder, amorphous, liquid or oily state is not possible because of this limitation. Although esterification or salt formation is carried out in order to obtain a single crystal, the resulting crystals are different forms of the original compound. Recently, the crystalline sponge method, ${ }^{1,2,3,4}$ which made it possible to elucidate non-crystalline compounds, including liquid or oily compounds have been reported. The structure elucidation of the reaction intermediates, an asymmetric catalyst, the reaction products and the natural products, and the determination of the absolute configuration were accomplished by using the crystalline sponge method. ${ }^{5}$ To apply this new method to drug discovery, the geometrical precision of the derived structure will be critical. The crystalline sponge method often requires geometrically restrained refinement, which hindered the high- precision analysis because large network complex including heavy atoms should be solved with a small target molecule absorbed in the void space of the complex at the same time.<smiles>COC(=O)c1ccccc1O</smiles>

1

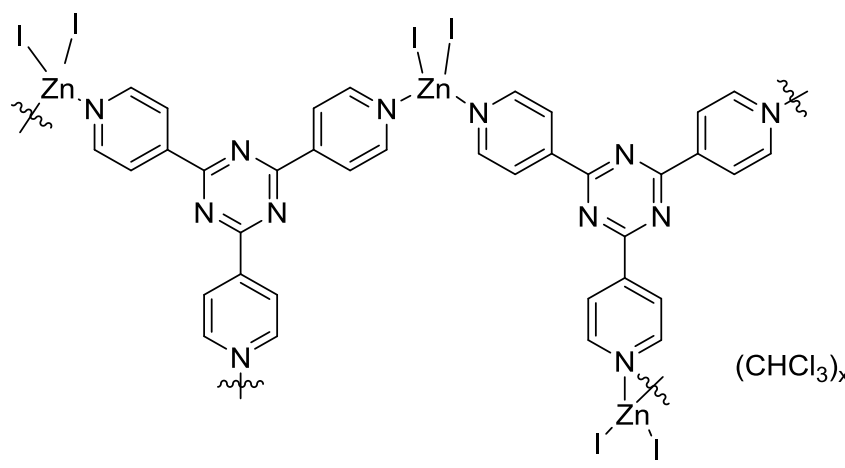

2

Figure 1. Methyl salicylate $\mathbf{1}$ inclusion in crystalline sponge $\mathbf{2}$.

Herein we report the high-resolution X-ray structure of methyl salicylate 1 (Figure 1), an oily compound at room temperature 
(melting point: $-8.6{ }^{\circ} \mathrm{C}$ and boiling point: $220-224{ }^{\circ} \mathrm{C}$ ), ${ }^{6}$ which was solved by using the crystalline sponge method, and the refined crystal structure without hard restraints. $\mathbf{1}$ is used as a liniment for muscle pain through the ages. To the best of our knowledge, only two crystal structures of this simple timehonored oily medicinal drug have been reported. The structure of 1 was solved as the ligand of porphyrin metal complexes in both structures. $^{7}$

In this experiment, the network complex $\left[\left(\mathrm{ZnI}_{2}\right)_{3}(\mathrm{tpt})_{2} \cdot x(\text { chloroform })\right]_{\mathrm{n}} \quad(\mathbf{2} ; \quad$ tpt $\quad=1,3,5$-tris $(4-$ pyridyl)triazine) was used as the crystalline sponge (Figure 1). 2 was prepared according to Clardy's method. ${ }^{2 a}$ One drop of $\mathbf{1}$ was added to crystalline sponge $\mathbf{2}$ placed on a petri dish. The crystalline sponge soaked with $\mathbf{1}$ was preserved at precisely controlled at $25{ }^{\circ} \mathrm{C}$ in an electric oven for 3 days. Careful observation with a polarizing microscope was performed to pick a high-quality and ideally sized single crystal called super crystal, which had absolutely no tiny cracks or wrinkles, for X-ray diffraction.

Single-crystal X-ray diffraction data were collected on a Bruker D8 VENTURE using $\mathrm{CuK} \alpha$ radiation. The structure was solved using SHELXT $^{8}$ and refined with SHELXL ${ }^{9}$ programs. All the non-hydrogen atoms were refined anisotropically. All the hydrogen atoms were refined with HFIX 43( $\mathrm{Ar}-\underline{\mathrm{H}}), 137\left(\mathrm{C}_{3}\right)$, 147( $(\underline{\mathrm{H}}), 33\left(\mathrm{CH}_{3}\right.$ for $\mathrm{D}, \mathrm{E}$ and $\left.\mathrm{F}\right), 83(\mathrm{OH}$ for $\mathrm{F})$. The existence of some unassigned molecular fragments in void spaces was suggested in many cases in this method. This was because of the low occupancy of the absorbed molecule and/or the presence of residual solvent. PLATON/SQUEEZE ${ }^{10}$ is the convenient program to eliminating the unassigned molecular fragments from the void spaces, however Spek, ${ }^{11}$ and Clardy ${ }^{2 a}$ do not recommend applying the program to the high-precision analysis. The use of the program requires extreme care. Therefore, to avoid use of PLATON/SQUEEZE, refinement using soft restraints for the anisotropy of the guest, solvent, and tpt or $\mathrm{ZnX}_{2}$ moiety, as well as hard restraints of bond lengths, bond angles, and planarity was necessary. It was noted that correct assignment of the molecules in the unassigned space independently of the restrained operation made it possible to solve the fine structure. Detailed discussion of the precise geometry of the molecule, including the bond lengths and bond angles affected by the unassigned space problem, was difficult in this method. We succeeded in solving the fine structure of methyl salicylate, which had almost no unassigned fragment and/or solvent in the void spaces, and discussed the precise geometry of the molecule. A closely packed nature of the molecules in void spaces is shown in Figure 2. ${ }^{2}$
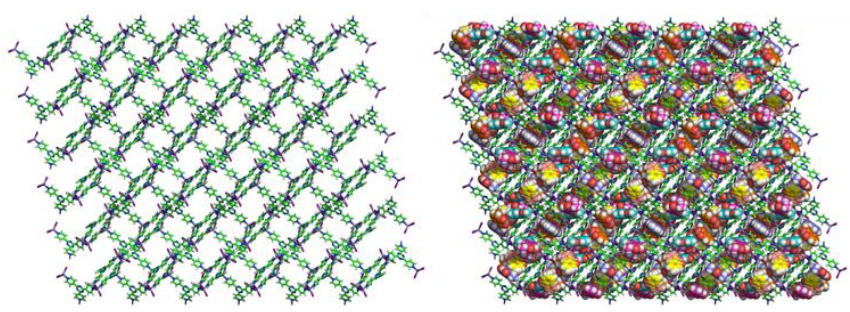

Figure 2. Void spaces of the network complex (left) and closely packed methyl salicylate molecules (right).

The crystalline sponge in which $\mathbf{1}$ was absorbed was monoclinic, exhibited $C 2 / c, Z=8, a=36.015(2) \AA, b=$ 14.7774(9) $\AA, c=31.248(2) \AA, \beta=102.216(2)^{\circ}, V=16254.1(18)$ $\AA^{3}$, and was almost identical to the crystal lattices previously reported $^{1,2 a}$.
Six independent molecules in the asymmetric unit were solved. Molecules of $\mathbf{1}$ having various occupancies are shown as A (blue, 100\%), B (deep pink, 100\%), C (yellow, 70\%), D (light pink, 30\%), E (purple, 100\%), and F (orange, 80\%) (Figures 3 and 4). All the occupancies were determined from the $F_{\mathrm{o}}-F_{\mathrm{c}}$ differential electron density maps shown in Figure 5. Three $\mathrm{ZnI}_{2}$, two tpt, and six independent molecules of $\mathbf{1}$ existed in the asymmetric unit (Figure 3$)^{13}$

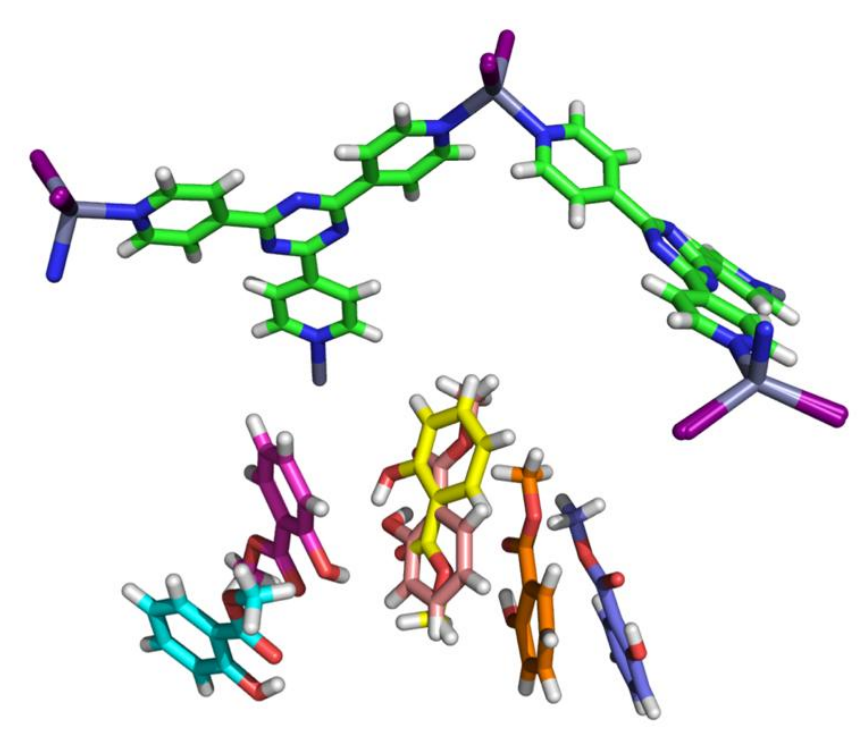

Figure 3. Crystal structures of $\mathbf{1}$ and $\mathbf{2}$ in the asymmetric unit. Blue, deep pink, yellow, light pink, purple, and orange are methyl
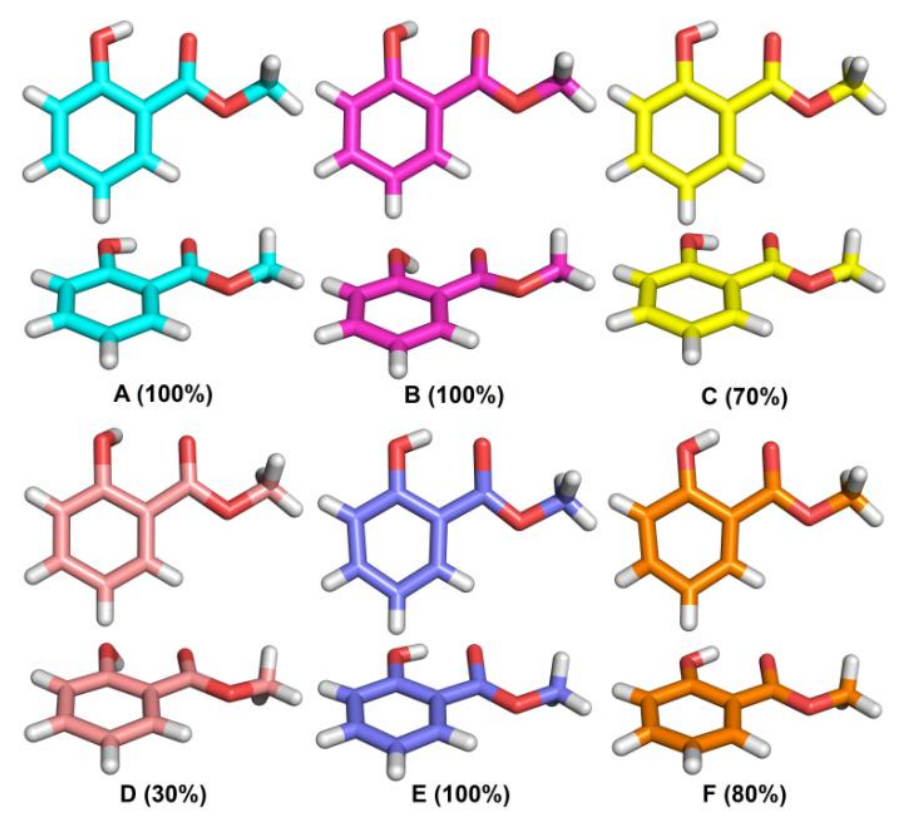

salicylates A, B, C, D, E, and F, respectively

Figure 4. Crystal structures of methyl salicylates A, B, C, D, E and F. Top: front view, bottom: side view. Value in parenthesis indicates occupancy.

Molecules A, B, and C were refined without any restraints. Molecules D, E, and $\mathrm{F}$ were refined without hard restraints related to the bond lengths and bond angles, although an isotopic restraint was applied. Disordered molecules C and D were found at the same location (Figure S2). Two kinds of molecules E 
overlapped with each other at the same location are ride on the special symmetry, inversion center, in the lattice (Figure S3). Due to the unassigned remaining electron density around molecule F, we could not determine the details of the disordered structures. Finally, we elucidated molecule F, which was the

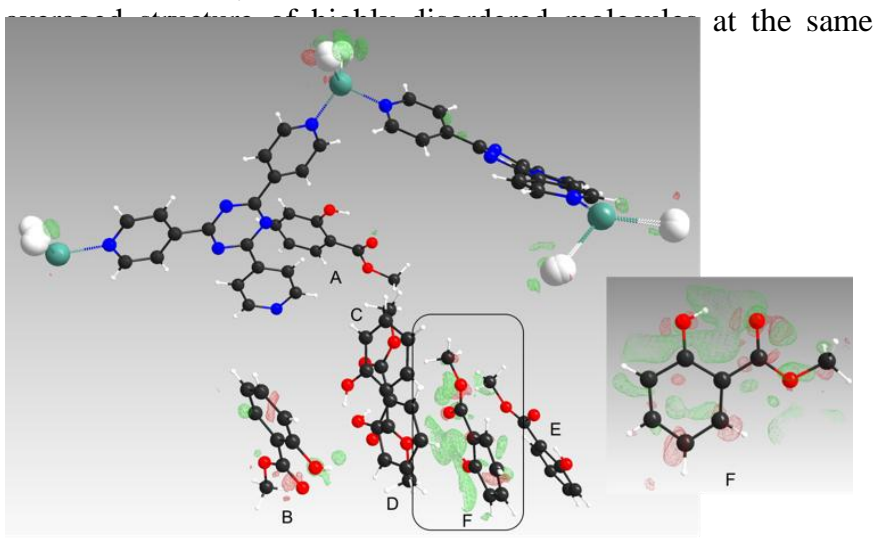

Figure 5. Differential electron density maps $\left(F_{\mathrm{O}}-F_{\mathrm{c}}(0.20 \mathrm{e} / \AA ̊ \AA 3)\right)$. Asymmetric unit (left) and partial enlarged view of molecule $F$ (right).

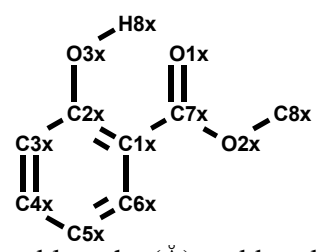

Table 1. Selected bond lengths $(\check{A})$ and bond angles $\left({ }^{\circ}\right)$ of methyl salicylates A, B, and C. ${ }^{[a]}$

\begin{tabular}{cccc}
\hline & $\mathrm{A}$ & $\mathrm{B}$ & $\mathrm{C}$ \\
\hline Benzene Ring & $\begin{array}{c}1.371(8) \sim \\
1.412(7)\end{array}$ & $\begin{array}{c}1.359(10) \sim \\
1.413(8)\end{array}$ & $\begin{array}{c}1.368(13) \sim \\
1.458(16)\end{array}$ \\
\hline $\mathrm{C} 1 \mathrm{x}-\mathrm{C} 7 \mathrm{x}$ & $1.455(7)$ & $1.465(7)$ & $1.475(13)$ \\
\hline $\mathrm{C} 2 \mathrm{x}-\mathrm{O} 3 \mathrm{x}$ & $1.338(6)$ & $1.356(6)$ & $1.387(13)$ \\
\hline $\mathrm{C} 7 \mathrm{x}=\mathrm{O} 1 \mathrm{x}$ & $1.212(6)$ & $1.229(7)$ & $1.229(11)$ \\
\hline $\mathrm{C} 7 \mathrm{x}-\mathrm{O} 2 \mathrm{x}$ & $1.326(6)$ & $1.322(7)$ & $1.305(12)$ \\
\hline $\mathrm{O} 2 \mathrm{x}-\mathrm{C} 8 \mathrm{x}$ & $1.433(7)$ & $1.433(7)$ & $1.459(10)$ \\
\hline $\begin{array}{c}\mathrm{O} 3 \mathrm{x}-\mathrm{H} 8 \mathrm{x}- \\
\mathrm{O} 1 \mathrm{x}\end{array}$ & 1.91 & 2.22 & 1.91 \\
\hline $\begin{array}{c}\mathrm{C} 1 \mathrm{x}-\mathrm{C} 7 \mathrm{x}- \\
\mathrm{O} 1 \mathrm{x}\end{array}$ & $124.1(5)$ & $122.3(5)$ & $121.9(10)$ \\
\hline $\begin{array}{c}\mathrm{C} 1 \mathrm{x}-\mathrm{C} 7 \mathrm{x}- \\
\mathrm{O} 2 \mathrm{x}\end{array}$ & $113.5(4)$ & $115.6(5)$ & $114.6(8)$ \\
\hline $\begin{array}{c}\mathrm{O} 1 \mathrm{x}-\mathrm{C} 7 \mathrm{x}- \\
\mathrm{O} 2 \mathrm{x}\end{array}$ & $122.4(5)$ & $122.0(5)$ & $123.5(9)$ \\
\hline
\end{tabular}

[a] X indicates methyl salicylate A, B or C.

We discuss herein the high-resolution three-dimensional structures of molecules A, B, and C, which were refined without any restraints. All the bond lengths were consistent with existing CCDC database. ${ }^{14}$ As shown in Table 1 , the bond lengths of the benzene ring were between $1.359(10)$ and $1.458(16) \AA$. At the ester moiety, $\mathrm{C} 7 \mathrm{x}=\mathrm{O} 1 \mathrm{x}$ bond length was between $1.212(6)$ and
1.229(11) $\AA$, and C7x-O2x bond length was between 1.305(12) and 1.326(6) $\AA$. The bond length of $\mathrm{C} 2 \mathrm{x}-\mathrm{O} 3 \mathrm{x}$, the root of the hydroxyl group, ranged from $1.338(6)$ to $1.387(13) \AA$. All hydroxyl groups formed intramolecular hydrogen bonds with the adjacent $\mathrm{O} 1 \mathrm{x}$ of the carbonyl groups. The benzene rings were flat, and $\mathrm{C} 1 \mathrm{x}, \mathrm{C} 7 \mathrm{x}, \mathrm{O} 1 \mathrm{x}$, and $\mathrm{O} 2 \mathrm{x}$ were located on the plane.

Next, we discuss the intermolecular interactions between molecules of $\mathbf{1}$ in the crystalline sponge. Similar to the previously reported coordination cages, ${ }^{15}$ tpt and absorbed molecules of $\mathbf{1}$ provided a highly aromatic environment, and planar molecules of 1 were stacked in layers (Figure 6). For example, C7A --- O3B (3.088(7) $\AA$ ), $\mathrm{CgB}$--- CgC (5.266(5) $\mathrm{A}), \mathrm{CgB}$--- CgD (5.171(12) $\AA), \mathrm{O} 2 \mathrm{C}$--- C6F (3.370(13) $\AA$ ), CgD --- CgF (4.157(13) $\AA$ ), and O1E --- C1F (3.21(5) $\AA$ ) were observed. ${ }^{16}$ These stackings were not ordered and seemed to be different from the usually observed parallel behavior. Homogeneous molecular interactions in biologically active small molecules, including such biomaterials as nucleic acid bases, amino acids, and steroids, which formed chain structures, were often observed in solution. ${ }^{17}$
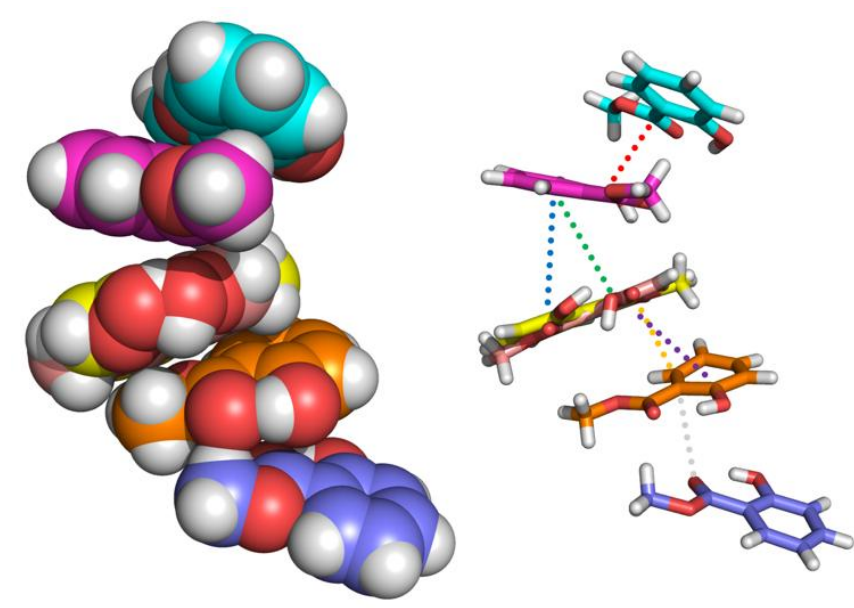

Figure 6. Space filling model of molecules A, B, C, D, E, and F stacked in layers. (left) Dashed lines show intermolecular interactions; red (C7A --- O3B), blue $(\mathrm{CgB}---\mathrm{CgC})$, green $(\mathrm{CgB}$--$\mathrm{CgD})$, orange $(\mathrm{O} 2 \mathrm{C}$--- $\mathrm{C} 6 \mathrm{~F})$, purple $(\mathrm{CgD}---\mathrm{CgF})$, and gray $(\mathrm{O} 1 \mathrm{E}-$ -- C1F). (right)

In conclusion, we solved the high-resolution X-ray structure of $\mathbf{1}$, a time-honored oily medicinal drug, by using the crystalline sponge method. In the crystalline sponge, six independent molecules of $\mathbf{1}$ existed in an asymmetric unit. The structure of $\mathbf{1}$, including the bond lengths and bond angles, was consistent with that in the CCDC database. All the methyl salicylate molecules were stacked in layers. By using the crystalline sponge method, the conformational diversity and the related specific homogeneous molecular interactions of methyl salicylate were clearly observed in the lone space of the framework. In this study, the precise structure determination by using the crystalline sponge method, which involved refining with almost no unassigned fragment and/or solvent in the void spaces and without hard restraints, was shown for the first time.

\section{Acknowledgments}

We are grateful to the JST-ACCEL program, which is funding part of this research. 


\section{References and notes}

1. (a) Inokuma, Y.; Yoshioka, S.; Ariyoshi, J.; Arai, T.; Hitora, Y.; Takada, K.; Matsunaga, S.; Rissanen, K.; Fujita, M. Nature 2013 495, 461-466; (b) Inokuma, Y.; Yoshioka, S.; Ariyoshi, J.; Arai, T.; Hitora, Y.; Takada, K.; Matsunaga, S.; Rissanen, K.; Fujita, M. Nature 2013, 501, 262; (c) Inokuma, Y.; Yoshioka, S.; Ariyoshi, J.; Arai, T.; Fujita, M. Nat. Protoc. 2014, 9, 246-252; (d) Hoshino, M.; Khutia A.; Xing H.; Inokuma, Y; Fujita, M. IUCrJ. 2016, 3, $139-151$.

2. (a) Ramadhar, T. R.; Zheng, S.-L.; Chen, Y.-S.; Clardy, J. Acta Crystallogr., Sect. A: Found. Adv. 2015, 71, 46-58; (b) Ramadhar T. R.; Zheng, S.-L.; Chen, Y.-S.; Clardy, J. Chem. Commun. 2015 , 51, $11252-11255$.

3. Sanna, E.; Escudero-Adán, E. C.; Bauzá, A.; Ballester, P.; Frontera, A.; Rotger, C.; Costa, A. Chem. Sci. 2015, 6, 54665472.

4. Ning, G-H.; Matsumura, K.; Inokuma, Y.; Fujita, M. Chem. Commun. 2016, 52, 7013 - 7015.

5. (a) Kamimura, D.; Urabe, D.; Nagatomo M.; Inoue, M. Org. Lett., 2013, 15, 5122-5125; (b) Vinogradova, E. V.; Müller, P.; Buchwald, S. L. Angew. Chem., Int. Ed. 2014, 53, 3125-3128; (c) O’Brien, A. G.; Maruyama, A.; Inokuma, Y.; Fujita, M.; Baran, P. S.; Blackmond, D. G. Angew. Chem., Int. Ed. 2014, 53, 1186811871; (d) Yoshioka, S.; Inokuma, Y.; Hoshino, M.; Sato, T.; Fujita, M. Chem. Sci. 2015, 6, 3765-3768; (e) Zigon, N.; Hoshino, M.; Yoshioka, S.; Inokuma, Y.; Fujita, M. Angew. Chem. Int. Ed. 2015, 54, 9033-9037; (f) Takizawa, S.; Kishi, K.; Yoshida, Y.; Mader, S.; Arteaga, F.; Lee, S.; Hoshino, M.; Rueping, M.; Fujita M.; Sasai, H. Angew. Chem., Int. Ed., 2015, 54, 15511-15515; (g) Urban, R. Brkljača, M. Hoshino, S. Lee, M. Fujita, Angew. Chem. Int. Ed. 2016, 55, 2678 - 2682; (h) Inokuma, Y.; Ukegawa, T.; Hoshino, M.; Fujita, M. Chem. Sci., 2016, 7, 3910-3913; (i) Cuenca, A. B.; Zigon, N.; Duplan, V.; Hoshino, M.; Fujita, M. Chem. Eur. J. 2016, 22, 4723 - 4726; (j) Duplan, V; Hoshino, M.; Li, W.; Honda, T.; Fujita, M. Angew. Chem., Int. Ed., 2016, 55, 4919-4923; (k) Matsuda, Y.; Mitsuhashi, T.; Lee, S.; Hoshino, M.; Mori, T .; Okada, M.; Zhang, H.; Hayashi, F.; Fujita, M.; Abe, I. Angew. Chem., Int. Ed., 2016, 55, 5785-5788;

6. O'Neil, J. M. In The Merck Index: An Encyclopedia of Chemicals, Drugs, and Biologicals 13th Ed.; Merck: New Jersey, 2006; pp 1090-1091.

7. A search (CSD Version 5.36 using the ConQuest program) hit ZITMEU and XAMHEY.
8. Sheldrick, G. M. Acta Crystallogr., Sect. A: Found. Adv. 2015, 71, 3-8.

9. Sheldrick, G. M. Acta Crystallogr., Sect. C: Struct. Chem. 2015, 71, 3-8.

10. Spek, A. L. Acta Crystallogr., Sect. C: Struct. Chem. 2015, 71, 918.

11. Spek, A. L. "The Extended PLATON/SQUEEZE Tool in the Context of Twinning and SHELXL2014" and "CIF, PLATON2014, SHELXL-2014, VALIDATION \& SQUEEZE", 23rd Congress of IUCr, Montreal, Aug. 2014.

12. PLATON/SQUEEZE shows the total potential solvent accessible void volume is $286.1 \AA^{3}$ and residual electrons count 19 in the unit cell.

13. Crystallographic data for $2 \cdot 1: \mathrm{C}_{70.4} \mathrm{H}_{58.4} \mathrm{I}_{6} \mathrm{~N}_{12} \mathrm{O}_{12.9} \mathrm{Zn}_{3} M=2236.40$, $D_{\text {calc }}=1.828{\mathrm{~g} \cdot \mathrm{cm}^{-3}}^{-3}$ GOF $=1.105, R_{1}=0.0289, w R_{2}=0.0843$ for all data. CCDC 1414043.

14. A search was perfomed by the Mogul 1.7 program (CSD Version 5.36).

15. (a) Yoshizawa, M.; Nakagawa, J.; Kumazawa, K.; Nagao, M.; Kawano, M. Ozeki, T.; Fujita, M. Angew. Chem. Int. Ed. 2005, 44, 1810-1813; (b) Yamauchi, Y.; Yoshizawa, M. Fujita, M. J. Am. Chem. Soc. 2008, 130, 5832-5833; (c) Sato, S.; Takeuchi, R.; Yagi-Utsumi, M.; Yamaguchi, T.; Yamaguchi, Y.; Kato, K.; Fujita, M. Chem. Comm. 2015, 51, 2540-2543; (d) Klosterman, J. K.; Yamauchi, Y.; Fujita, M. Chem. Soc. Rev. 2009, 38, 17141725 .

16. Cg means the centroid of benzene moiety in 1 .

17. (a) kunimura, M.; Sakamoto, S.; Yamaguchi, K. Org. Lett. 2002, 4, 347-350; (b) Sakamoto, S.; Yamaguchi, K.; Angew. Chem. Int. Ed. 2003, 42, 905-908; (c) Shikii, K. Sakamoto, S.; Seki, H. Utsumi, H.; Yamaguchi, K. Tetrahedron 2004, 60, 3487-3492; (d) Yamaguchi, K. J. Mass Spectrom. 2003, 38, 473-490. 


\section{Graphical Abstract}

To create your abstract, type over the instructions in the template box below.

Fonts or abstract dimensions should not be changed or altered.

High-resolution X-ray structure of methyl salicylate, a time-honored oily medicinal

Leave this area blank for abstract info. drug, solved by crystalline sponge method

Masatoshi Kawahata, Shinsuke Komagawa, Kazuaki Ohara, Makoto Fujita and Kentaro Yamaguchi

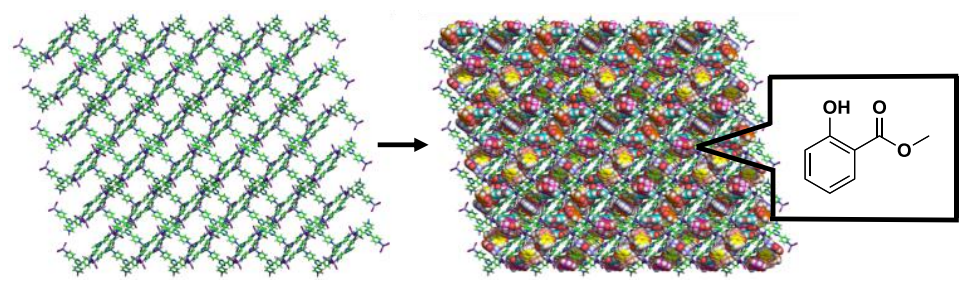

